\title{
Inter-domain Horizontal Gene Transfer of Nickel-binding Superoxide Dismutase
}

Kevin M. Sutherland ${ }^{1, *}$, Lewis M. Ward ${ }^{1}$, Chloé-Rose Colombero ${ }^{1}$, David T. Johnston ${ }^{1}$

${ }^{1}$ Department of Earth and Planetary Science, Harvard University, Cambridge, MA 02138

$5 \quad *$ Correspondence to KMS: ksutherland@,fas.harvard.edu

\section{Abstract}

8 The ability of aerobic microorganisms to regulate internal and external concentrations of the 9 reactive oxygen species (ROS) superoxide directly influences the health and viability of cells.

10 Superoxide dismutases (SODs) are the primary regulatory enzymes that are used by 11 microorganisms to degrade superoxide. SOD is not one, but three separate, non-homologous 12 enzymes that perform the same function. Thus, the evolutionary history of genes encoding for 13 different SOD enzymes is one of convergent evolution, which reflects environmental selection

14 brought about by an oxygenated atmosphere, changes in metal availability, and opportunistic

15 horizontal gene transfer (HGT). In this study we examine the phylogenetic history of the protein 16 sequence encoding for the nickel-binding metalloform of the SOD enzyme (SodN). A comparison

17 of organismal and SodN protein phylogenetic trees reveals several instances of HGT, including 18 multiple inter-domain transfers of the $\operatorname{sod} N$ gene from the bacterial domain to the archaeal domain.

19 Nearly half of the archaeal members with sodN live in the photic zone of the marine water column.

20 The $\operatorname{sodN}$ gene is widespread and characterized by apparent vertical gene transfer in some 21 sediment-associated lineages within the Actinobacteriota (Actinobacteria) and Chloroflexota

22 (Chloroflexi) phyla, suggesting the ancestral sodN likely originated in one of these clades before

23 expanding its taxonomic and biogeographic distribution to additional microbial groups in the 24 surface ocean in response to decreasing iron availability. In addition to decreasing iron quotas, 25 nickel-binding SOD has the added benefit of withstanding high reactant and product ROS 26 concentrations without damaging the enzyme, making it particularly well suited for the modern 27 surface ocean. 


\section{Introduction}

Molecular oxygen in the ground state is a diradical. The presence of these two unpaired electrons in parallel spin makes $\mathrm{O}_{2}$ susceptible to univalent reduction, which will lead to the

31 formation of reactive oxygen species (ROS) (Fridovich, 1978). When $\mathrm{O}_{2}$ interacts with an electron

32 donor such as a reduced metal or organic carbon and univalent reduction occurs, superoxide $\left(\mathrm{O}_{2}{ }^{-}\right.$

33 ) is formed. This reaction occurs in association with the core metabolic and physiological functions

34 of microorganisms. Superoxide is produced at photosystem I during photosynthesis (Asada, 2006),

35 at multiple locations along the electron transport chain in aerobic respiration (Larosa \& Remacle,

36 2018), and on the outer membrane of cells for a range of purposes including nutrient acquisition

37 (Rose et al., 2008), cell signaling (Buetler et al., 2004), redox homeostasis (Diaz et al., 2019; Yuasa

38 et al., 2020), and cell growth and proliferation (Carlioz \& Touati, 1986; Oda et al., 1995; Saran,

39 2003). Superoxide is a highly reactive molecule that typically has a lifetime on the order of a few

40 minutes under physiological conditions (Diaz et al., 2013). It can further act as an oxidant or

41 reductant in a wide range of consequential biogeochemical reactions involving nutrients, metals, organic carbon, and nitrogen species.

The evolution of oxygenic photosynthesis and subsequent Great Oxygenation Event ( 2.32.4 Gya) greatly increased the energy available to fuel microbial metabolisms (Fischer et al., 2016;

45 Ward et al., 2019). However, increasing oxygen levels is in many ways a double-edged sword.

46 The potential to produce superoxide and other ROS would have increased in parallel with 47 atmospheric oxygen levels, which can have a myriad of detrimental effects on cells (Taverne et 48 al., 2018). The reactivity of superoxide with a wide range of organic moieties and metal cofactors can damage various cell components, including lipid membrane peroxidation and iron release from iron-sulfur clusters (Longo et al., 1999; Radi et al., 1991). Superoxide production can precede the formation of hydroxyl radical, which itself can have devastating effects on biomolecules (Buxton et al., 1988; Oda et al., 1992). The ability to manage and mitigate the deleterious consequences of superoxide and its downstream effects and reaction products is an inescapable challenge of life evolving in the presence of molecular oxygen.

Superoxide dismutase is the primary biological tool that microorganisms use to degrade

56 superoxide, both within the cell membrane and in the environment. The presence of at least one 57 copy of superoxide dismutase in the genome of all extant aerobic organisms (and many anaerobes) 
name "superoxide dismutase" is used as a catch-all term to describe four different metalloforms of three distinct enzyme families that have no known homology. These four metalloforms include manganese (Mn) (gene: $\operatorname{sod} A$, protein: SodA, enzyme: MnSOD), iron (Fe) (gene: sodB, protein: SodB, enzyme: FeSOD), copper and zinc (CuZn) (gene: sodC, protein: SodC, enzyme: CuZnSOD), and nickel (Ni) (gene: sodN, protein: SodN, enzyme: NiSOD)(Dupont et al., 2008; Wolfe-Simon et al., 2005). Only the Mn- and Fe-binding metalloforms have demonstrable homology (including a cambialistic isoform that can function with either Fe or Mn (Lancaster et al., 2004)), thus, superoxide dismutase is likely an example of convergent evolution in which life reinvented the wheel three separate times (No, 2017).

The concentration of oxygen, its influence on metal redox state, and the availability of each metal cofactor in the environment all present important selective pressures on determining the distribution of these different SOD-encoding genes spatially and throughout Earth History. While the true antiquity of these three enzyme families is not known with certainty, the relative ages have been inferred from a combination of phylogenetic arguments and likely environmental conditions on the ancient surface Earth. The FeSOD/MnSOD enzyme family is thought to be the most ancient of these three enzyme families (Hatchikian \& Henry, 1977; Yost \& Fridovich, 1973). This notion is evidenced by the observation that $\operatorname{sod} A / \operatorname{sod} B$ is phylogenetically wide-spread, and because low atmospheric oxygen in the early Earth would have favored high concentrations of dissolved $\mathrm{Fe}^{2+}$ and $\mathrm{Mn}^{2+}$ (Wolfe-Simon et al., 2005). Conversely, CuZnSOD, thought to be the youngest of the three enzyme families, is widespread in higher plants and animals, present in some bacteria, and absent from archaea and protists (Case, 2017). This metalloform of SOD can also be localized to the cytoplasm, the nucleus, mitochondrial intermembrane space, chloroplasts, and extracellular space (Case, 2017; Weisiger \& Fridovich, 1973). The presumed younger age of the CuZnSOD is

82 supported by its relative scarcity among microorganisms, and the fact that $\mathrm{Cu}$ and $\mathrm{Zn}$ would have

83 both been highly insoluble in an low-oxygen world (Case, 2017; Saito et al., 2003; Wolfe-Simon 84 et al., 2005).

Intermediate in antiquity to the MnSOD/FeSOD and CuZnSOD enzymes, and the primary focus of this study, is Ni-binding superoxide dismutase. NiSOD is the most recently discovered of these three enzyme families (discovered in 1996), and has been the subject of less study than the other two enzyme families (Youn et al., 1996). The evolution and proliferation of NiSOD is 
Simon et al., 2005). In fact, NiSOD is the most common metalloform of SOD in modern marine bacteria (Sheng et al., 2014). The abundance of NiSOD among marine Cyanobacteria has been used to suggest that NiSOD may have originated among marine phototrophs (Case, 2017; WolfeSimon et al., 2005). However, more recent work suggests that sodN originated within the

94 Actinobacteriota clade before appearing in other clades through a combination of vertical and

95 horizontal gene transfer (Schmidt et al., 2009). Currently, sodN is thought to be present primarily

96 in bacterial clades, however, some instances of $\operatorname{sod} N$ in photosynthetic eukaryotes have been

97 identified (Cuvelier et al., 2010). To date, sodN has not been identified in archaea (Sheng et al., 98 2014).

Given the ever-expanding availability of quality genomic data and analysis tools, we revisit the phylogeny of the NiSOD protein to better understand its evolutionary history and its

101 distribution across the tree of life. We examine the role of vertical and horizontal gene transfer in

102 the controlling the phylogeny of NiSOD sequences. With this information, we aim to better

103 understand the environmental pressures that select for NiSOD over other SOD genes and contextualize the history of this gene within the broader scope of global biogeochemical cycles.

\section{Methods}

107 A reference database was constructed containing a single high-quality genome from every genus 108 of bacteria and archaea for which one is available based on the GTDB database (Parks et al., 2018, 109 2020). A list of all genomes included in the GTDB database was downloaded from the GTDB 110 servers (https://data.ace.uq.edu.au/public/gtdb/data/releases/). Genomes that did not meet current 111 metrics for high quality (e.g. completeness $<90 \%$ or contamination $>5 \%$, (Bowers et al., 2017))

112 were removed. This list was finally dereplicated to select a single genome of the highest available 113 completeness from every genus. Genomes were then downloaded from the NCBI WGS and

114 Genbank databases. This genome database was used to search for homologs of SodN and other 115 proteins using the tblastn function of BLAST+ (Camacho et al., 2009). For organismal 116 phylogenies, concatenated ribosomal protein phylogenies following methods from Hug et al. 117 (2016) (Hug et al., 2016). Protein sequences were aligned with MUSCLE (Edgar, 2004) and 118 phylogenetic trees were produced using RAxML v.8.2.12 (Stamatakis, 2014) on the Cipres 119 Science Gateway (Miller et al., 2010). Node support was calculated using transfer bootstrap 120 support with BOOSTER (Lemoine et al., 2018). Trees were visualized using the Interactive Tree 
121 of Life Viewer (Letunic \& Bork, 2016). Histories of horizontal gene transfer were assessed via

122 incongruence of organismal and metabolic protein phylogenies as described previously (e.g.

123 (Doolittle, 1986; Ward et al., 2020; Ward \& Shih, 2020)). Assessment of genomic neighborhood

124 of sodN genes was performed on the RAST platform (Aziz et al., 2008). In order to verify that

125 NiSOD presence was authentic and not a case of false positives (i.e. gene presence in

126 metagenome-assembled genomes due to contamination, e.g. (Ward et al., 2018)), we repeated

127 analyses with a more stringent quality cutoff of a maximum of $3.5 \%$ contamination as determined

128 by CheckM (Parks et al., 2015).

\section{Results}

We have produced the most complete phylogeny of NiSOD proteins available. The 132 phylogenies of the organisms identified in this study and their respective SodN protein sequences 133 are presented in Figures 1 and 2, respectively. This SodN phylogeny expands substantially on the 134 small collection of characterized NiSOD-producing isolates to include many lineages known only 135 or primarily from metagenome-assembled genomes (e.g. Patescibacteria) as well as cultured 136 organisms in which the presence of NiSOD was previously undescribed (e.g. diverse 137 Proteobacteria and Actinobacteriota). This more comprehensive view of the distribution of NiSOD 138 provides a much more complete context for interpreting the evolutionary history of this enzyme 139 family. At present, no homologous outgroup to the NiSOD protein family is known, and as a result

140 it impossible to robustly root the NiSOD phylogeny. For ease of viewing Figure 2 is shown with 141 an arbitrary midpoint root, but this is not intended to imply directionality of evolution.

142 Nonetheless, our results provide valuable understanding to evolutionary relatedness between 143 NiSOD sequences even if we are unable to pinpoint the origin of this enzyme family.

144 The presence of a small number of deep clades is readily visible in the NiSOD phylogeny.

145 In particular, much of the diversity of NiSOD sequences belongs to a large clade made up primarily 146 of sequences from Actinobacteriota, but also containing large clusters of sequences from 147 Cyanobacteria and smaller lineages from other organisms (bottom half of Figure 2). The remainder 148 of NiSOD diversity belongs to a somewhat smaller but more diverse clade made up largely of 149 Chloroflexota sequences interspersed with sequences from Patescibacteria, Proteobacteria, and 150 other organisms (top half of Figure 2). While each of these clades contains sequences from multiple 151 bacterial phyla (and, surprisingly, multiple archaeal phyla), these clades are made up of a plurality 
152 of and bounded by lineages of Actinobacterota and Chloroflexota, respectively. With few 153 exceptions (e.g. Cyanobacteria), NiSOD sequences from a particular phylum are polyphyletic, 154 scattered in multiple lineages separated by many sequences from other phyla. Moreover, the 155 topology of phylogenetic relationships both within and between phyla are largely incongruent with 156 organismal relationships, indicating many instances of interphylum horizontal gene transfer.

In contrast to previous claims (Sheng et al., 2014), we found that NiSOD are not absent from the archaeal domain. In fact, several clades of archaeal NiSOD exist, scattered throughout the enzyme phylogeny (Figure 2). The lack of reciprocal monophyly between bacterial and archaeal NiSOD sequences, and the incongruence between organismal and protein phylogenies

161 (Figure 1, Figure 2), strongly suggests that the distribution of NiSOD genes throughout the tree of 162 life is the result of multiple instances of interdomain horizontal gene transfer.

\section{Discussion}

Horizontal gene transfer (HGT) is commonplace in the microbial world. It is invoked to explain the distribution of a wide variety of genes that play a role in all aspects of metabolism and 167 physiology. Evidence of inter-domain horizontal gene transfer, however, is much less 168 commonplace. Generally speaking, the frequency of horizontal gene transfer between prokaryotes 169 is thought to increase with increasing genetic similarity, meaning inter-domain horizontal gene 170 transfer should be the rarest genetic transfer (Andam \& Gogarten, 2011). In fact, clear instances 171 of horizontal gene transfer between archaea and bacteria are fleeting and thought to be quite rare 172 (Avni \& Snir, 2020). It is clear from this study that NiSOD has indeed undergone multiple 173 instances of horizontal gene transfer, including several instances of transfer from the bacterial 174 domain to the archaeal domain.

175 NiSOD sequences are distributed throughout the bacterial domain, with most protein 176 diversity distributed between two large clades made up primarily of Actinobacteriota and 177 Chloroflexota. Substantial diversity of sequences derived from other bacterial and archaeal taxa 178 appears interspersed within these two clades, apparently reflecting a long history of horizontal 179 gene transfer within and between deep taxonomic groups including at the phylum and domain 180 level. While support values for some shallow nodes are relatively poor (e.g. within closely related 181 clades of Actinobacteriota sequences), support values for deep nodes including those between 182 archaeal and bacterial lineages are robust, providing strong confidence in interpretations of 
183 horizontal gene transfer. Because of our stringent quality cutoff for metagenome-assembled 184 genomes (MAGs), we can confidently assert that the organismal source of NiSOD proteins is 185 accurate, and does not reflect contamination or incorrect recruitment of sequences into MAGs, 186 further strengthening interpretations of HGT.

187 Many apparent instances of HGT of NiSOD_-including the bulk of interdomain transfer 188 events - appear to have occurred between taxa that tend to inhabit similar niches within the same 189 environment. For example, most Chloroflexota NiSOD sequences are from members of the 190 Dehalocoiccoidia class. Members of Dehalocoiccoidia are abundant and diverse in marine 191 sediment, terrestrial soil, and groundwater primarily as anaerobic heterotrophs (Taş et al., 2010; 192 Wasmund et al., 2016). Nested within the Chloroflexota NiSOD sequences are at least three 193 clusters of sequences from the Patescibacteria. Nested even deeper within Patescibacteria NiSOD 194 clades are a few sequences derived from archaea including the Woesearchaea. Both Patescibacteria 195 and Woesearchaea are thought to exploit similar strategies in the terrestrial subsurface as 196 symbionts with highly reduced genomes and cell sizes (Brown et al., 2015; Castelle et al., 2015). 197 This suggests the possibility that communities of predominantly anaerobic heterotrophs in 198 terrestrial sediment may have exchanged NiSOD genes repeatedly over geologic time, likely as an 199 adaptation to tolerate trace amounts of oxidants. This appears to have resulted in HGT of NiSOD 200 from Chloroflexota to Patescibacteria in at least three events, followed by two transfers from 201 Patescibacteria to Woesearchaea. In this case, it appears that colocalization and overlapping 202 metabolic strategies has enabled repeated HGT between lineages that have diverged on the 203 superphylum and even the domain level.

204 Similarly, interdomain HGT of NiSOD appears to have occurred between organisms in 205 shared environments with similar life strategies. An example of this is seen within the 206 Actinobacteriota clade of NiSOD sequences. Here, NiSOD sequences derived from the archaeal 207 Poseidoniales clade appear nested within a deeper group of bacterial Marinisomata sequences. 208 Both Marinisomata and Poseidoniales are primarily known to exist as water column heterotrophs, 209 with Poseidoniales primarily restricted to the photic zone while Marinisomata exist throughout the 210 water column (Huang \& Wang, 2020; Rinke et al., 2019). This suggests a possible route of 211 transmission of NiSOD genes from marine sediment Actinobacteriota, to water column 212 Marinisomata, and ultimately to surface ocean Poseidoniales. A similar transmission process 213 through different taxa moving up the water column may have led to the acquisition of NiSOD by 
214 Cyanobacteria. However, Cyanobacteria and Poseidoniales NiSOD sequences are not closely 215 related, suggesting that NiSOD sequences were introduced into the photic zone multiple times 216 from multiple lineages. This repeated, directional migration of NiSOD genes through the 217 environment, rather than extensive sharing of a single set of NiSOD genes simply within the photic 218 zone, highlights that the successful horizontal transfer of genes can require more than simple 219 colocalization of organisms and that multiple routes of transfer can be occurring into and within 220 an environment at any given time.

221 There are two likely candidates for the clade in which $\operatorname{sod} N$ originated: Actinobacteriota 222 and Chloroflexota. The $\operatorname{sodN}$ gene is widely distributed across both clades, and the phylogeny of 223 the SodN protein largely resembles the organismal tree of these two clades. In the absence of a 224 known outgroup, it is not formally possible to root SodN protein phylogenies (Figure 2 is 225 arbitrarily midpoint rooted for clarity). As a result we cannot conclusively determine the origin or 226 earliest representatives of the SodN enzyme. However, the abundance, diversity, and phylogenetic 227 relationships of SodN sequences from Actinobacterota and Chloroflexota makes them prime 228 candidates for the originators or earliest adopters of SodN. As previously highlighted, the 229 Actinobacteriota clade encompasses organisms that live in a variety of environments, many of 230 which are found in soil and sediment. The Chloroflexota phylum also contains incredible diversity 231 in metabolism and environmental requirements. Notably, this phylum includes members that are 232 thermophilic, heterotrophic, autotrophic, aerobic, and anaerobic (Islam et al., 2019).

233 Representatives of the class Dehalococcoidia are well represented among the Chloroflexota 234 members with $\operatorname{sodN}$; these organisms are primarily found in terrestrial and marine sedimentary 235 environments (Wasmund et al., 2014). Anaerolineae is the second most well represented 236 Chloroflexota class in sodN diversity. This class contains members isolated from marine sediment, 237 aquifers, and wastewater (Yamada \& Sekiguchi, 2009). Although this class has been previously 238 thought to include primarily obligate anaerobes that make a living from fermentation, several 239 members contain genes for respiration (Hemp et al., 2015; Pace et al., 2015; Ward et al., 2015). 240 The presence of NiSOD in diverse members of these two deeply rooted classes of Chloroflexota 241 suggests the possibility that NiSOD was present in their last common ancestor. Molecular clock 242 analyses have suggested that Anaerolineae and Dehalococcoidia diverged $\sim 2.2$ Gya (Shih et al., 243 2017), providing an indirect estimate for the antiquity of this enzyme family. 
Comparison of organismal and SodN protein phylogenies can provide some limited insight into the timing of NiSOD evolution. If, as discussed above, the root of the NiSOD tree is near the branch separating the Chloroflexota and Actinobacterota clades (i.e. the midpoint root shown in Figure 2), this suggests that NiSOD was acquired by early members of these clades and has subsequently been vertically inherited into crown groups. Both Actinobacterota and Chloroflexota are phyla with obligately anaerobic basal lineages that are thought to have originated in Archean time before the Great Oxygenation Event, subsequently acquired aerobic respiration, and underwent radiation of class-level lineages during early Proterozoic time (Lewin et al., 2016; Shih et al., 2017). It therefore follows that NiSOD originated at about this time, most likely under low oxygen conditions in marine sediment or the water column. Though it may seem logical to constrain the timing of the evolution of NiSOD with the GOE and associated introduction of significant oxygen to marine environments, small amounts of oxygen can be produced by abiotic processes including photolysis or radiolysis of water - providing an evolutionary impetus for SOD evolution decoupled from biological oxygen production. The origin of NiSOD in late Archean or early Proterozoic time is further consistent with changing marine Ni availability through Earth history. Dissolved Ni concentrations have previously been hypothesized to be on the order of 400 $\mathrm{nM}$ in the Archaean ocean, decreasing to $200 \mathrm{nM}$ by 2.5 Gya (Konhauser et al., 2009, 2015). These concentration estimates are more than 2 orders of magnitude greater than modern seawater concentrations (Sclater et al., 1976). Whether the ancestral NiSOD evolved in the marine water column or in underlying sediment, it almost certainly evolved in an environment where Ni exceeds modern marine concentrations.

There are several reasons why the presence $\operatorname{sod} N$ in a microbial genome may provide an advantage for organisms over its Fe-binding counterpart. One curious aspect of NiSOD is that it is the only metalloform whose metal cofactor does not react with superoxide as a hydrated ion.

268 While the "ping-pong" mechanism of catalysis is shared by all SODs (i.e. higher valent metal center oxidize superoxide, lower valent metal center reduces superoxide in an alternating fashion),

270 the redox potential of $\mathrm{Ni}(\mathrm{II} / \mathrm{III})$ redox pair is tuned to the appropriate redox potential by its 271 coordination within the enzyme (Herbst et al., 2009). Therefore, the presence of Ni and its 272 availably is not influenced by $\mathrm{O}_{2}$ and ROS in the same way that Fe would be. The concentration 273 of soluble Fe in seawater has decreased as a result of atmospheric oxygenation. Although estimates 274 vary, Fe concentrations likely dropped from $\sim 100 \mu \mathrm{M}$ in Archaean seawater, to low $\mu \mathrm{M}$ or high 
$\mathrm{nM}$ concentrations in the Proterozoic, to the near $1 \mathrm{nM}$ dissolved Fe seen in the open ocean today 276 (Holland, 1984). Today, Fe can be a limiting nutrient for primary productivity in many surface ocean regions, stemming from its use as cofactor in many different essential enzymes (Behrenfeld et al., 1996; Behrenfeld \& Kolber, 1999). The utilization of NiSOD over FeSOD under such iron limitation provides a competitive advance in its ability to reduce iron quotas.

The superoxide-dismutating activity of both FeSOD and NiSOD are inhibited by excess hydrogen peroxide, one of the two primary products of the dismutation reaction (Sheng et al., 2014). However, the $\mathrm{H}_{2} \mathrm{O}_{2}$ inhibition of FeSOD and NiSOD work in fundamentally different ways. FeSOD inhibition by $\mathrm{H}_{2} \mathrm{O}_{2}$ occurs through irreversible peroxidative damage of the enzyme that proceeds through a Fenton-type reaction. Inhibition of NiSOD, conversely, operates by reducing $\mathrm{Ni}(\mathrm{III})$ to $\mathrm{Ni}(\mathrm{II})$ without damaging the enzyme itself (Herbst et al., 2009). This inhibition is reversible, and SOD catalytic activity is restored once hydrogen peroxide levels drop below the inhibition threshold. Similar to FeSOD, CuZnSOD may also be irreversibly inhibited by excess $\mathrm{H}_{2} \mathrm{O}_{2}$ (Gabbianelli et al., 2004). While MnSOD is not known to be inhibited by $\mathrm{H}_{2} \mathrm{O}_{2}$, its SOD activity is lessened slightly at higher concentrations of superoxide (Sheng et al., 2014), which, to our knowledge, has not been demonstrated for the other metalloforms.

In the surface ocean, superoxide and hydrogen peroxide production is wide-spread and results from a combination of light-dependent and light-independent reactions (Diaz et al., 2019;

294 Sutherland et al., 2019; Vermilyea et al., 2010). Surface superoxide concentrations range from low $295 \mathrm{pM}$ to several $\mathrm{nM}$ in the open ocean, with higher concentrations typically found in productive surface waters (Sutherland, Grabb, et al., 2020; Sutherland, Wankel, et al., 2020). In some cases, superoxide may approach 100-200 nM in productive coral reef ecosystems (Diaz et al., 2016;

298 Grabb et al., 2019). Hydrogen peroxide has a lifetime in seawater that is $\sim 3$ orders of magnitude 299 longer than superoxide (i.e. typical $\mathrm{H}_{2} \mathrm{O}_{2}$ lifetime is hours to days), and correspondingly has 300 concentrations that range from low $\mathrm{nM}$ in the deep ocean to as high as several hundred $\mathrm{nM}$ in 301 productive sunlit surface water (Hopwood et al., 2017; Yuan \& Shiller, 2005). The ability of 302 NiSOD to catalyze superoxide dismutation at near diffusion limited rates and withstand elevated 303 concentrations of hydrogen peroxide may make it uniquely suited for microbial fitness in the 304 surface ocean with modern oxygen levels. 
There is observational evidence to support the notion that not all SOD enzymes are perfect replacements for one another, even when cofactor concentrations are replete. For example, one study examined the growth of two strains of Synechococcus under low and high Ni concentrations to compare Ni requirements for NiSOD and urease (Dupont et al., 2008). In that study, one strain's genome encoded for only NiSOD, while the other's genome encoded for both NiSOD and CuZnSOD. The authors showed that under low Ni concentrations and adequate fixed nitrogen

311 (resulting in reduced $\mathrm{Ni}$ quotas for urease), $\mathrm{Cu} / \mathrm{ZnSOD}$ could not replace NiSOD activity. 312 However, not all cyanobacteria have NiSOD; FeSOD is represented across cyanobacterial 313 diversity. Even still, this observation demonstrates that there are enzyme characteristics beyond 314 the metal cofactor identity that select for certain SOD metalloforms; these are not well known and should be the target of future study.

317 for proteorhodopsins. All nine of these organisms belong to the Poseidoniales clade, which is one 318 of the most widespread archaeal groups in surface ocean waters (Rinke et al., 2019). The selective 319 pressures experienced by these archaea, including nutrient availability, light levels, and ROS 320 levels, mirrors those experienced by cyanobacteria such as Synechococcus and Prochlorococcus, 321 suggesting that the acquisition and expression of $\operatorname{sodN}$ plays a key role in microbial success in the 322 modern ocean.

\section{Summary and Conclusion}

Using the Genome Taxonomy Database, we examined the phylogenetic relation of the nickel-binding metalloform of superoxide dismutase to better understand its evolutionary history 327 and biogeography in the context of environmental constraints. We compared organismal 328 phylogenies and NiSOD gene phylogenies to demonstrate that NiSOD has undergone multiple 329 instances of inter-domain horizontal gene from bacteria to archaea. Actinobacteriota and 330 Chloroflexota as two clades in which NiSOD is pervasive and in which the organismal phylogeny 331 resembles that of the $\operatorname{sodN}$ gene. As such, these two clades are the most likely candidates for the 332 evolutionary root of $\operatorname{sodN}$. The distribution of NiSOD sequence diversity is consistent with one or 333 more vertical migrations in biogeography, starting in soil or marine sediment and migrating to the 334 photic zone. The acquisition of $\operatorname{sod} N$ as a means to mitigate iron-limitation is consistent with the 335 biogeochemical history of the marine environment, however, other factors such as hardiness 
336 against damage by the product hydrogen peroxide may also contribute to its proliferation in the 337 surface ocean.

\section{Acknowledgements:}

340 This work was funded by an Agouron Institute geobiology postdoctoral fellowship (KMS), the

341 Simons Foundation (Grant Number 653687 to LMW), and Harvard University (CRC, DTJ).

\section{Figures:}

344 Fig 1: Organismal phylogenetic tree determined using concatenated ribosomal protein sequences

345 of organisms from the Genome Taxonomy Database that contain a sodN gene. We note that there

346 are slightly fewer organisms in the organismal tree than in the SodN protein tree (Figure 2), this is

347 due to either low completeness or poorly aligned concatenated ribosomal sequences. See methods

348 for a complete description of tree production and quality cutoff metrics.

350 Fig 2: SodN protein sequence tree for organisms containing at least one copy of the sodN gene in 351 the Genome Taxonomy Database. 
bioRxiv preprint doi: https://doi.org/10.1101/2021.01.12.426412; this version posted January 13,2021 . The copyright holder for this preprint (which was not certified by peer review) is the author/funder, who has granted bioRxiv a license to display the preprint in perpetuity. It is made available under aCC-BY-NC-ND 4.0 International license.

\section{Figure 1:}
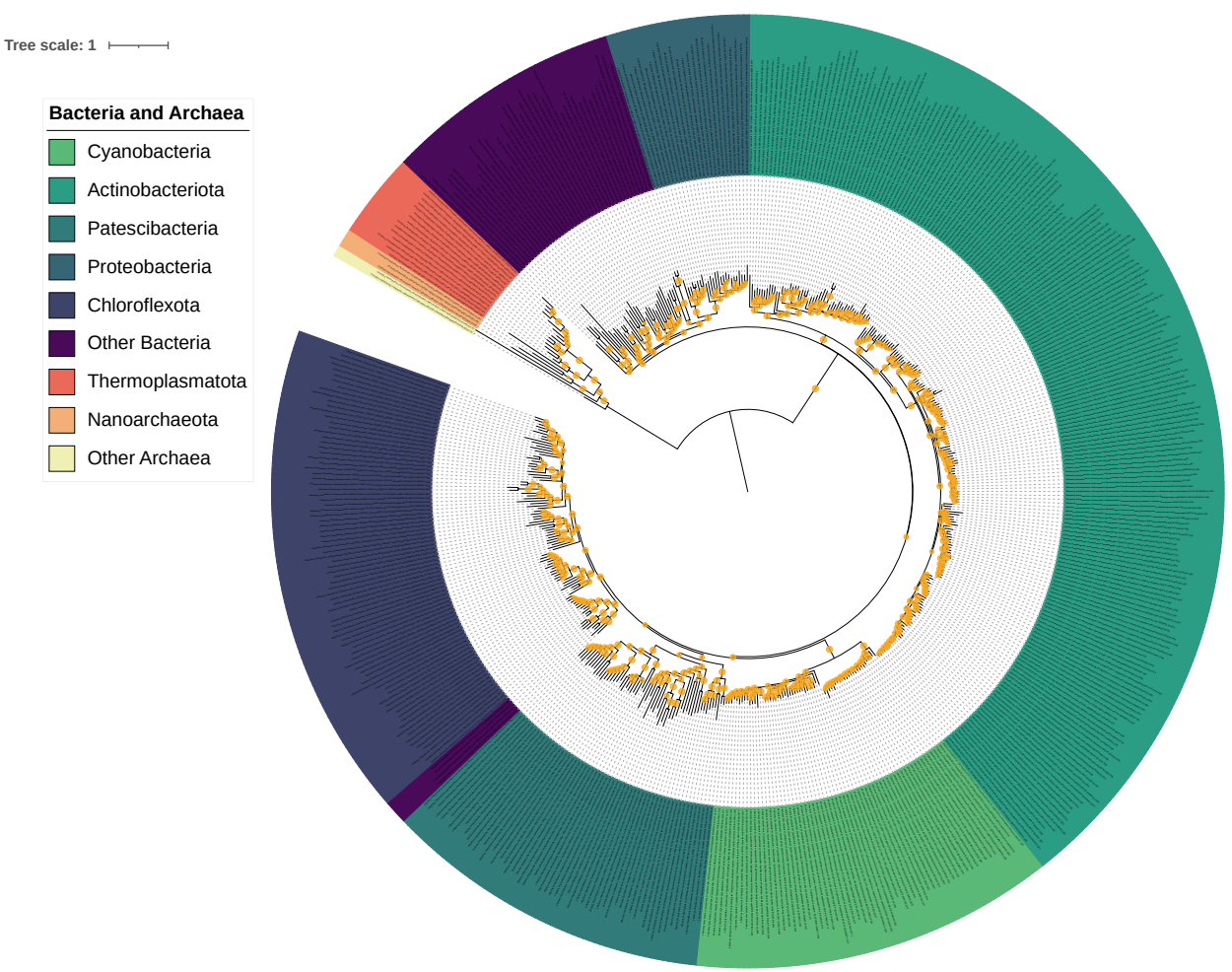
bioRxiv preprint doi: https://doi.org/10.1101/2021.01.12.426412; this version posted January 13, 2021. The copyright holder for this preprint (which was not certified by peer review) is the author/funder, who has granted bioRxiv a license to display the preprint in perpetuity. It is made available under aCC-BY-NC-ND 4.0 International license.

\section{Figure 2:}
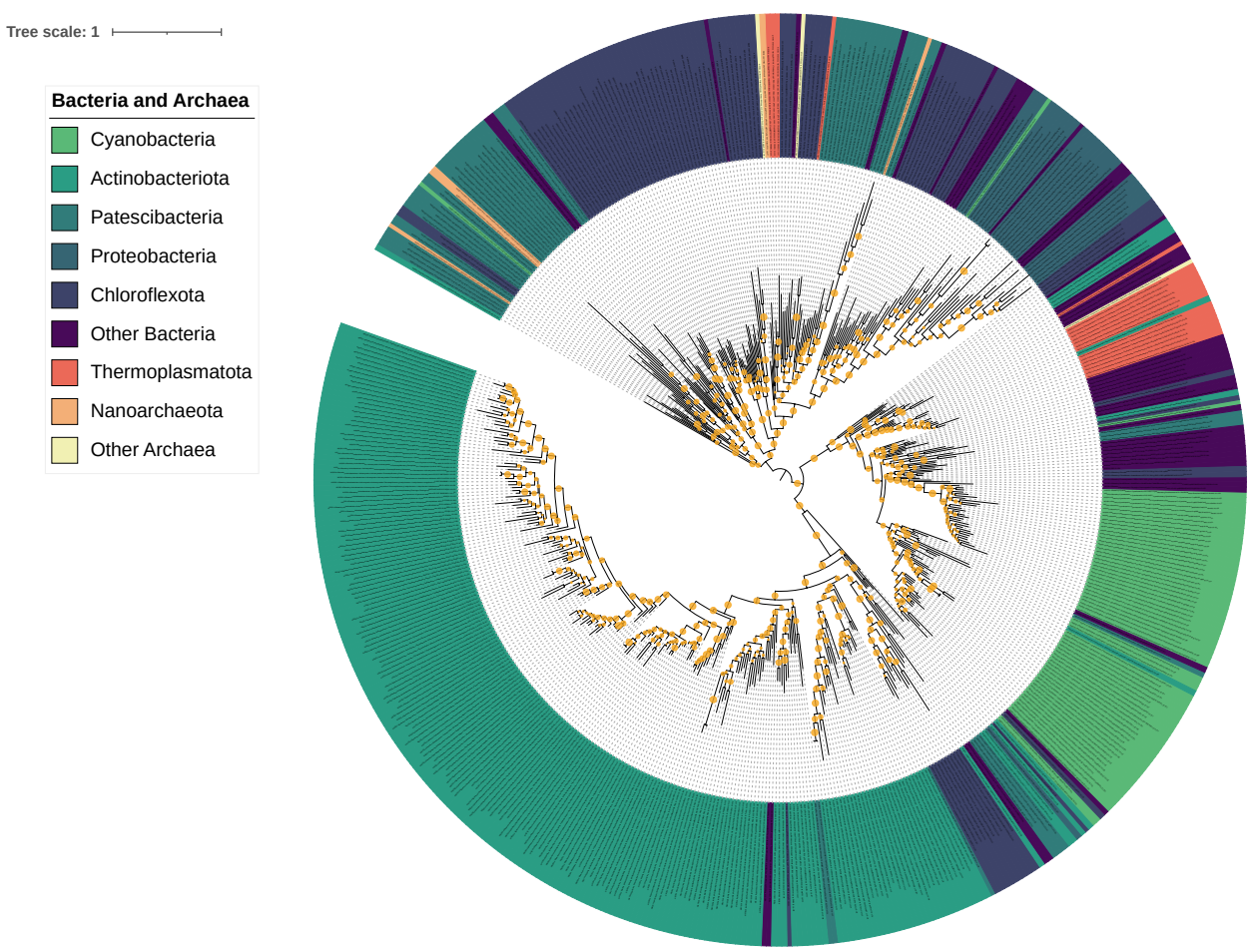


\section{References:}

Andam, C. P., \& Gogarten, J. P. (2011). Biased gene transfer in microbial evolution. Nature Reviews Microbiology, 9(7), 543-555. https://doi.org/10.1038/nrmicro2593

Asada, K. (2006). Production and scavenging of reactive oxygen species in chloroplasts and their functions. Plant Physiology, 141(2), 391-396. https://doi.org/10.1104/pp.106.082040

Avni, E., \& Snir, S. (2020). A New Phylogenomic Approach For Quantifying Horizontal Gene Transfer Trends in Prokaryotes. Scientific Reports, 10(1), 12425. https://doi.org/10.1038/s41598-020-62446-5

Aziz, R. K., Bartels, D., Best, A. A., DeJongh, M., Disz, T., Edwards, R. A., Formsma, K., Gerdes, S., Glass, E. M., Kubal, M., Meyer, F., Olsen, G. J., Olson, R., Osterman, A. L., Overbeek, R. A., McNeil, L. K., Paarmann, D., Paczian, T., Parrello, B., ... Zagnitko, O. (2008). The RAST Server: Rapid Annotations using Subsystems Technology. BMC Genomics, 9(1), 75. https://doi.org/10.1186/1471-2164-9-75

Behrenfeld, M. J., Bale, A. J., Kolber, Z. S., Aiken, J., \& Falkowski, P. G. (1996). Confirmation of iron limitation of phytoplankton photosynthesis in the equatorial Pacific Ocean. Nature, 383(6600), 508-511. https://doi.org/10.1038/383508a0

Behrenfeld, M. J., \& Kolber, Z. S. (1999). Widespread Iron Limitation of Phytoplankton in the South Pacific Ocean. Science, 283(5403), 840-843. https://doi.org/10.1126/science.283.5403.840

Bowers, R. M., Kyrpides, N. C., Stepanauskas, R., Harmon-Smith, M., Doud, D., Reddy, T. B. K., Schulz, F., Jarett, J., Rivers, A. R., Eloe-Fadrosh, E. A., Tringe, S. G., Ivanova, N. N., Copeland, A., Clum, A., Becraft, E. D., Malmstrom, R. R., Birren, B., Podar, M., Bork, P., ... Woyke, T. (2017). Minimum information about a single amplified genome (MISAG) and a metagenome-assembled genome (MIMAG) of bacteria and archaea. Nature Biotechnology, 35(8), 725-731. https://doi.org/10.1038/nbt.3893

Brioukhanov, A. L., \& Netrusov, A. I. (2004). Catalase and Superoxide Dismutase: Distribution, Properties, and Physiological Role in Cells of Strict Anaerobes. Biochemistry (Moscow), 69(9), 949-962. https://doi.org/10.1023/B:BIRY.0000043537.04115.d9

Brown, C. T., Hug, L. A., Thomas, B. C., Sharon, I., Castelle, C. J., Singh, A., Wilkins, M. J., Wrighton, K. C., Williams, K. H., \& Banfield, J. F. (2015). Unusual biology across a group comprising more than 15\% of domain Bacteria. Nature, 523(7559), 208-211. https://doi.org/10.1038/nature14486

Buetler, T. M., Krauskopf, A., \& Ruegg, U. T. (2004). Role of superoxide as a signaling molecule. Physiology, 19(3), 120-123.

Buxton, G. V, Greenstock, C. L., Helman, W. P., \& Ross, A. B. (1988). Critical Review of rate constants for reactions of hydrated electrons, hydrogen atoms and hydroxyl radicals $(\cdot \mathrm{OH} / \cdot \mathrm{O}-$ in Aqueous Solution. Journal of Physical and Chemical Reference Data, 17(2), 513-886. https://doi.org/10.1063/1.555805

Camacho, C., Coulouris, G., Avagyan, V., Ma, N., Papadopoulos, J., Bealer, K., \& Madden, T. L. (2009). BLAST+: architecture and applications. BMC Bioinformatics, 10(1), 421. https://doi.org/10.1186/1471-2105-10-421

Carlioz, A., \& Touati, D. (1986). Isolation of superoxide dismutase mutants in Escherichia coli: is superoxide dismutase necessary for aerobic life? The EMBO Journal, 5(3), 623-630. https://doi.org/10.1002/j.1460-2075.1986.tb04256.x

Case, A. J. (2017). On the origin of superoxide dismutase: an evolutionary perspective of superoxide-mediated redox signaling. Antioxidants, 6(4), 82. 
404

405

406

407

408

409

410

411

412

413

414

415

416

417

418

419

420

421

422

423

424

425

426

427

428

429

430

431

432

433

434

435

436

437

438

439

440

441

442

443

444

445

446

447

448

449

Castelle, C. J., Wrighton, K. C., Thomas, B. C., Hug, L. A., Brown, C. T., Wilkins, M. J., Frischkorn, K. R., Tringe, S. G., Singh, A., Markillie, L. M., Taylor, R. C., Williams, K. H., \& Banfield, J. F. (2015). Genomic Expansion of Domain Archaea Highlights Roles for Organisms from New Phyla in Anaerobic Carbon Cycling. Current Biology, 25(6), 690701. https://doi.org/https://doi.org/10.1016/j.cub.2015.01.014

Cuvelier, M. L., Allen, A. E., Monier, A., McCrow, J. P., Messié, M., Tringe, S. G., Woyke, T., Welsh, R. M., Ishoey, T., Lee, J.-H., Binder, B. J., DuPont, C. L., Latasa, M., Guigand, C., Buck, K. R., Hilton, J., Thiagarajan, M., Caler, E., Read, B., ... Worden, A. Z. (2010). Targeted metagenomics and ecology of globally important uncultured eukaryotic phytoplankton. Proceedings of the National Academy of Sciences, 107(33), 14679-14684. https://doi.org/10.1073/pnas.1001665107

Diaz, J. M., Hansel, C. M., Apprill, A., Brighi, C., Zhang, T., Weber, L., McNally, S., \& Xun, L. P. (2016). Species-specific control of external superoxide levels by the coral holobiont during a natural bleaching event. Nature Communications, 7. https://doi.org/10.1038/ncomms 13801

Diaz, J. M., Hansel, C. M., Voelker, B. M., Mendes, C. M., Andeer, P. F., \& Zhang, T. (2013). Widespread Production of Extracellular Superoxide by Heterotrophic Bacteria. Science, 340(6137), 1223-1226. https://doi.org/10.1126/science.1237331

Diaz, J. M., Plummer, S., Hansel, C. M., Andeer, P. F., Saito, M. A., \& Mcilvin, M. R. (2019). NADPH-dependent extracellular superoxide production is vital to photophysiology in the marine diatom Thalassiosira oceanica. 116(33). https://doi.org/10.1073/pnas.1821233116

Doolittle, R. F. (1986). Of URFs and ORFs: A primer on how to analyze derived amino acid sequences. University Science Books.

Dupont, C. L., Barbeau, K., \& Palenik, B. (2008). Ni Uptake and Limitation in Marine Synechococcus Strains. Applied and Environmental Microbiology, 74(1), 23-31. https://doi.org/10.1128/AEM.01007-07

Edgar, R. C. (2004). MUSCLE: multiple sequence alignment with high accuracy and high throughput. Nucleic Acids Research, 32(5), 1792-1797. https://doi.org/10.1093/nar/gkh340

Fischer, W. W., Hemp, J., \& Johnson, J. E. (2016). Evolution of Oxygenic Photosynthesis. Annual Review of Earth and Planetary Sciences, 44(1), 647-683.

https://doi.org/10.1146/annurev-earth-060313-054810

Fridovich, I. (1978). The biology of oxygen radicals. Science, 201(4359), 875-880. https://doi.org/10.1126/science.210504

Gabbianelli, R., D’Orazio, M., Pacello, F., O’Neill, P., Nicolini, L., Rotilio, G., \& Battistoni, A. (2004). Distinctive functional features in prokaryotic and eukaryotic $\mathrm{Cu}, \mathrm{Zn}$ superoxide dismutases. Biological Chemistry, 385(8), 749-754. https://doi.org/10.1515/bc.2004.091

Grabb, K. C., Kapit, J., Wankel, S. D., Manganini, K., Apprill, A., Armenteros, M., \& Hansel, C. M. (2019). Development of a Handheld Submersible Chemiluminescent Sensor: Quantification of Superoxide at Coral Surfaces. Environmental Science \& Technology, 53(23), 13850-13858. https://doi.org/10.1021/acs.est.9b04022

Hatchikian, E. C., \& Henry, Y. A. (1977). An iron-containing superoxide dismutase from the strict anaerobe Desulfovibrio desulfuricans (Norway 4). Biochimie, 59(2), 153-161. https://doi.org/https://doi.org/10.1016/S0300-9084(77)80286-1

Hemp, J., Ward, L. M., Pace, L. A., \& Fischer, W. W. (2015). Draft Genome Sequence of Levilinea saccharolytica KIBI-1, a Member of the Chloroflexi Class Anaerolineae. Microbiology Resource Announcements, 3(6). https://doi.org/10.1128/genomeA.01357-15 
Herbst, R. W., Guce, A., Bryngelson, P. A., Higgins, K. A., Ryan, K. C., Cabelli, D. E., Garman, S. C., \& Maroney, M. J. (2009). Role of Conserved Tyrosine Residues in NiSOD Catalysis: A Case of Convergent Evolution. Biochemistry, 48(15), 3354-3369. https://doi.org/10.1021/bi802029t

Holland, H. D. (1984). The chemical evolution of the atmosphere and oceans. Princeton University Press.

Hopwood, M. J., Rapp, I., Schlosser, C., \& Achterberg, E. P. (2017). Hydrogen peroxide in deep waters from the Mediterranean Sea, South Atlantic and South Pacific Oceans. Scientific Reports, 7, 43436.

Huang, J.-M., \& Wang, Y. (2020). Genomic differences within the phylum Marinimicrobia: From waters to sediments in the Mariana Trench. Marine Genomics, 50, 100699. https://doi.org/https://doi.org/10.1016/j.margen.2019.100699

Hug, L. A., Baker, B. J., Anantharaman, K., Brown, C. T., Probst, A. J., Castelle, C. J., Butterfield, C. N., Hernsdorf, A. W., Amano, Y., Ise, K., Suzuki, Y., Dudek, N., Relman, D. A., Finstad, K. M., Amundson, R., Thomas, B. C., \& Banfield, J. F. (2016). A new view of the tree of life. Nature Microbiology, 1(5), 16048.

https://doi.org/10.1038/nmicrobiol.2016.48

Islam, Z. F., Cordero, P. R. F., Feng, J., Chen, Y.-J., Bay, S. K., Jirapanjawat, T., Gleadow, R. M., Carere, C. R., Stott, M. B., Chiri, E., \& Greening, C. (2019). Two Chloroflexi classes independently evolved the ability to persist on atmospheric hydrogen and carbon monoxide. The ISME Journal, 13(7), 1801-1813. https://doi.org/10.1038/s41396-019-0393-0

Konhauser, K. O., Pecoits, E., Lalonde, S. V, Papineau, D., Nisbet, E. G., Barley, M. E., Arndt, N. T., Zahnle, K., \& Kamber, B. S. (2009). Oceanic nickel depletion and a methanogen famine before the Great Oxidation Event. Nature, 458(7239), 750-753. https://doi.org/10.1038/nature07858

Konhauser, K. O., Robbins, L. J., Pecoits, E., Peacock, C., Kappler, A., \& Lalonde, S. V. (2015). The Archean Nickel Famine Revisited. Astrobiology, 15(10), 804-815. https://doi.org/10.1089/ast.2015.1301

Lancaster, V. L., LoBrutto, R., Selvaraj, F. M., \& Blankenship, R. E. (2004). A Cambialistic Superoxide Dismutase in the Thermophilic Photosynthetic Bacterium Chloroflexus aurantiacus. Journal of Bacteriology, 186(11), 3408-3414. https://doi.org/10.1128/JB.186.11.3408-3414.2004

Larosa, V., \& Remacle, C. (2018). Insights into the respiratory chain and oxidative stress. Bioscience Reports, 38(5), BSR20171492. https://doi.org/10.1042/BSR20171492

Lemoine, F., Domelevo Entfellner, J.-B., Wilkinson, E., Correia, D., Dávila Felipe, M., De Oliveira, T., \& Gascuel, O. (2018). Renewing Felsenstein's phylogenetic bootstrap in the era of big data. Nature, 556(7702), 452-456. https://doi.org/10.1038/s41586-018-0043-0

Letunic, I., \& Bork, P. (2016). Interactive tree of life (iTOL) v3: an online tool for the display and annotation of phylogenetic and other trees. Nucleic Acids Research, 44(W1), W242W245. https://doi.org/10.1093/nar/gkw290

Lewin, G. R., Carlos, C., Chevrette, M. G., Horn, H. A., McDonald, B. R., Stankey, R. J., Fox, B. G., \& Currie, C. R. (2016). Evolution and Ecology of Actinobacteria and Their Bioenergy Applications. Annual Review of Microbiology, 70, 235-254. https://doi.org/10.1146/annurev-micro-102215-095748

Longo, V. D., Liou, L.-L., Valentine, J. S., \& Gralla, E. B. (1999). Mitochondrial Superoxide Decreases Yeast Survival in Stationary Phase. Archives of Biochemistry and Biophysics, 
365(1), 131-142. https://doi.org/https://doi.org/10.1006/abbi.1999.1158

Miller, M. A., Pfeiffer, W., \& Schwartz, T. (2010). Creating the CIPRES Science Gateway for inference of large phylogenetic trees. 2010 Gateway Computing Environments Workshop (GCE), 1-8. https://doi.org/10.1109/GCE.2010.5676129

No, M. S. (2017). Reinventing the Wheel: The NiSOD Story. The Biological Chemistry of Nickel, 10, 170.

Oda, T., Akaike, T., Sato, K., Ishimatsu, A., Takeshita, S., Muramatsu, T., \& Maeda, H. (1992). Hydroxyl radical generation by red tide algae. Archives of Biochemistry and Biophysics, 294(1), 38-43. https://doi.org/https://doi.org/10.1016/0003-9861(92)90133-H

Oda, T., Moritomi, J., Kawano, I., Hamaguchi, S., Ishimatsu, A., \& Muramatsu, T. (1995). Catalase-and superoxide dismutase-induced morphological changes and growth inhibition in the red tide phytoplankton Chattonella marina. Bioscience, Biotechnology, and Biochemistry, 59(11), 2044-2048.

Pace, L. A., Hemp, J., Ward, L. M., \& Fischer, W. W. (2015). Draft Genome of Thermanaerothrix daxensis GNS-1, a Thermophilic Facultative Anaerobe from the Chloroflexi Class Anaerolineae. Microbiology Resource Announcements, 3(6). https://doi.org/10.1128/genomeA.01354-15

Parks, D. H., Chuvochina, M., Chaumeil, P.-A., Rinke, C., Mussig, A. J., \& Hugenholtz, P. (2020). A complete domain-to-species taxonomy for Bacteria and Archaea. Nature Biotechnology, 38(9), 1079-1086. https://doi.org/10.1038/s41587-020-0501-8

Parks, D. H., Chuvochina, M., Waite, D. W., Rinke, C., Skarshewski, A., Chaumeil, P.-A., \& Hugenholtz, P. (2018). A standardized bacterial taxonomy based on genome phylogeny substantially revises the tree of life. Nature Biotechnology, 36(10), 996-1004. https://doi.org/10.1038/nbt.4229

Parks, D. H., Imelfort, M., Skennerton, C. T., Hugenholtz, P., \& Tyson, G. W. (2015). CheckM: assessing the quality of microbial genomes recovered from isolates, single cells, and metagenomes. Genome Research, 25(7), 1043-1055. https://doi.org/10.1101/gr.186072.114

Radi, R., Beckman, J. S., Bush, K. M., \& Freeman, B. A. (1991). Peroxynitrite-induced membrane lipid peroxidation: The cytotoxic potential of superoxide and nitric oxide. Archives of Biochemistry and Biophysics, 288(2), 481-487. https://doi.org/https://doi.org/10.1016/0003-9861(91)90224-7

Rinke, C., Rubino, F., Messer, L. F., Youssef, N., Parks, D. H., Chuvochina, M., Brown, M., Jeffries, T., Tyson, G. W., Seymour, J. R., \& Hugenholtz, P. (2019). A phylogenomic and ecological analysis of the globally abundant Marine Group II archaea (Ca. Poseidoniales ord. nov.). The ISME Journal, 13(3), 663-675. https://doi.org/10.1038/s41396-018-0282-y

Rose, A. L., Webb, E. A., Waite, T. D., \& Moffett, J. W. (2008). Measurement and implications of nonphotochemically generated superoxide in the equatorial Pacific Ocean. Environmental Science \& Technology, 42(7), 2387-2393. https://doi.org/10.1021/es7024609

Saito, M. A., Sigman, D. M., \& Morel, F. M. M. (2003). The bioinorganic chemistry of the ancient ocean: the co-evolution of cyanobacterial metal requirements and biogeochemical cycles at the Archean-Proterozoic boundary? Inorganica Chimica Acta, 356, 308-318. https://doi.org/https://doi.org/10.1016/S0020-1693(03)00442-0

Saran, M. (2003). To what end does nature produce superoxide? NADPH oxidase as an autocrine modifier of membrane phospholipids generating paracrine lipid messengers. Free Radical Research, 37(10), 1045-1059. 
Schmidt, A., Gube, M., Schmidt, A., \& Kothe, E. (2009). In silico analysis of nickel containing superoxide dismutase evolution and regulation. Journal of Basic Microbiology, 49(1), 109118. https://doi.org/10.1002/jobm.200800293

Sclater, F. R., Boyle, E., \& Edmond, J. M. (1976). On the marine geochemistry of nickel. Earth and Planetary Science Letters, 31(1), 119-128. https://doi.org/https://doi.org/10.1016/0012821X(76)90103-5

Sheng, Y., Abreu, I. A., Cabelli, D. E., Maroney, M. J., Miller, A.-F., Teixeira, M., \& Valentine, J. S. (2014). Superoxide Dismutases and Superoxide Reductases. Chemical Reviews, 114(7), 3854-3918. https://doi.org/10.1021/cr4005296

Shih, P. M., Ward, L. M., \& Fischer, W. W. (2017). Evolution of the 3-hydroxypropionate bicycle and recent transfer of anoxygenic photosynthesis into the Chloroflexi. Proceedings of the National Academy of Sciences, 114(40), 10749-10754. https://doi.org/10.1073/pnas.1710798114

Stamatakis, A. (2014). RAxML version 8: a tool for phylogenetic analysis and post-analysis of large phylogenies. Bioinformatics, 30(9), 1312-1313. https://doi.org/10.1093/bioinformatics/btu033

Sutherland, K. M., Coe, A., Gast, R. J., Plummer, S., Suffridge, C. P., Diaz, J. M., Bowman, J. S., Wankel, S. D., \& Hansel, C. M. (2019). Extracellular superoxide production by key microbes in the global ocean. Limnology and Oceanography, 64(6), 2679-2693. https://doi.org/10.1002/lno.11247

Sutherland, K. M., Grabb, K. C., Karolewski, J. S., Plummer, S., Farfan, G. A., Wankel, S. D., Diaz, J. M., Lamborg, C. H., \& Hansel, C. M. (2020). Spatial Heterogeneity in ParticleAssociated, Light-Independent Superoxide Production within Productive Coastal Waters. Journal of Geophysical Research: Oceans, $n / a(\mathrm{n} / \mathrm{a})$, e2020JC016747. https://doi.org/10.1029/2020JC016747

Sutherland, K. M., Wankel, S. D., \& Hansel, C. M. (2020). Dark biological superoxide production as a significant flux and sink of marine dissolved oxygen. Proceedings of the National Academy of Sciences, 117(7), 3433-3439. https://doi.org/10.1073/pnas.1912313117

Taş, N., Van Eekert, M. H. A., De Vos, W. M., \& Smidt, H. (2010). The little bacteria that can diversity, genomics and ecophysiology of 'Dehalococcoides' spp. in contaminated environments. Microbial Biotechnology, 3(4), 389-402. https://doi.org/10.1111/j.17517915.2009.00147.x

Taverne, Y. J., Merkus, D., Bogers, A. J., Halliwell, B., Duncker, D. J., \& Lyons, T. W. (2018). Reactive Oxygen Species: Radical Factors in the Evolution of Animal Life: A molecular timescale from Earth's earliest history to the rise of complex life. BioEssays, 40(3), 1700158.

Vermilyea, A. W., Paul Hansard, S., \& Voelker, B. M. (2010). Dark production of hydrogen peroxide in the Gulf of Alaska. Limnology and Oceanography, 55(2), 580-588. https://doi.org/10.4319/1o.2010.55.2.0580

Ward, L. M., Hemp, J., Pace, L. A., \& Fischer, W. W. (2015). Draft Genome Sequence of Leptolinea tardivitalis YMTK-2, a Mesophilic Anaerobe from the Chloroflexi Class Anaerolineae. Microbiology Resource Announcements, 3(6). https://doi.org/10.1128/genomeA.01356-15

Ward, L. M., Lingappa, U. F., Grotzinger, J. P., \& Fischer, W. W. (2020). Microbial mats in the Turks and Caicos Islands reveal diversity and evolution of phototrophy in the Chloroflexota 
order Aggregatilineales. Environmental Microbiome, 15(1), 9. https://doi.org/10.1186/s40793-020-00357-8

Ward, L. M., Rasmussen, B., \& Fischer, W. W. (2019). Primary Productivity Was Limited by Electron Donors Prior to the Advent of Oxygenic Photosynthesis. Journal of Geophysical Research: Biogeosciences, 124(2), 211-226. https://doi.org/10.1029/2018JG004679

Ward, L. M., \& Shih, P. M. (2020). Granick Revisited: Synthesizing Evolutionary and Ecological Evidence for the Late Origin of Bacteriochlorophyll via Ghost Lineages and Horizontal Gene Transfer. BioRxiv. https://doi.org/10.1101/2020.09.01.277905

Ward, L. M., Shih, P. M., \& Fischer, W. W. (2018). MetaPOAP: presence or absence of metabolic pathways in metagenome-assembled genomes. Bioinformatics, 34(24), 42844286. https://doi.org/10.1093/bioinformatics/bty510

Wasmund, K., Cooper, M., Schreiber, L., Lloyd, K. G., Baker, B. J., Petersen, D. G., Jørgensen, B. B., Stepanauskas, R., Reinhardt, R., Schramm, A., Loy, A., \& Adrian, L. (2016). SingleCell Genome and Group-Specific dsrAB Sequencing Implicate Marine Members of the Class Dehalococcoidia (Phylum Chloroflexi) in Sulfur Cycling. MBio, 7(3). https://doi.org/10.1128/mBio.00266-16

Wasmund, K., Schreiber, L., Lloyd, K. G., Petersen, D. G., Schramm, A., Stepanauskas, R., Jørgensen, B. B., \& Adrian, L. (2014). Genome sequencing of a single cell of the widely distributed marine subsurface Dehalococcoidia, phylum Chloroflexi. The ISME Journal, 8(2), 383-397. https://doi.org/10.1038/ismej.2013.143

Weisiger, R. A., \& Fridovich, I. (1973). Superoxide dismutase organelle specificity. Journal of Biological Chemistry, 248(10), 3582-3592.

Wolfe-Simon, F., Grzebyk, D., Schofield, O., \& Falkowski, P. G. (2005). The Role and Evolution of Superoxide Dismutases in Algae. Journal of Phycology, 41(3), 453-465. https://doi.org/10.1111/j.1529-8817.2005.00086.x

Yamada, T., \& Sekiguchi, Y. (2009). Cultivation of Uncultured Chloroflexi Subphyla: Significance and Ecophysiology of Formerly Uncultured Chloroflexi "Subphylum I" with Natural and Biotechnological Relevance. Microbes and Environments, advpub, 908180110. https://doi.org/10.1264/jsme2.ME09151S

Yost, F. J., \& Fridovich, I. (1973). An iron-containing superoxide dismutase from Escherichia coli. Journal of Biological Chemistry, 248(14), 4905-4908.

Youn, H.-D., Kim, E.-J., Roe, J.-H., Hah, Y. C., \& Kang, S.-O. (1996). A novel nickelcontaining superoxide dismutase from Streptomyces spp. Biochemical Journal, 318(3), 889-896. https://doi.org/10.1042/bj3180889

Yuan, J., \& Shiller, A. M. (2005). Distribution of hydrogen peroxide in the northwest Pacific Ocean. Geochemistry, Geophysics, Geosystems, 6(9). https://doi.org/10.1029/2004GC000908

Yuasa, K., Shikata, T., Kitatsuji, S., Yamasaki, Y., \& Nishiyama, Y. (2020). Extracellular secretion of superoxide is regulated by photosynthetic electron transport in the noxious redtide-forming raphidophyte Chattonella antiqua. Journal of Photochemistry and Photobiology B: Biology, 205, 111839. https://doi.org/https://doi.org/10.1016/j.jphotobiol.2020.111839 